POLICY DISCUSSION PAPERS

\title{
Oil Prices, Monetary Policy, and the Macroeconomy
}

by Charles T. Carlstrom and Timothy S. Fuerst 


\section{Oil Prices, Monetary Policy, and the Macroeconomy}

by Charles T. Carlstrom and Timothy S. Fuerst

Every U.S. recession since 1971 has been preceded by two things: an oil price shock and an increase in the federal funds rate. Bernanke, Gertler, and Watson $(1997,2004)$ investigated how much oil price shocks have contributed to output growth by asking the following counterfactual question: Empirically how much would we expect oil price increases to have contributed to output growth if the Fed had kept the rate constant instead of letting it increase? They concluded that, at most, half of the observed output declines can be attributed to oil price increases. Most were actually caused by funds rate increases. A problem with their empirical analysis, however, is that it implicitly assumes that the Fed can continually "fool" the public. That is, the funds rate is led constant even though the public actually expects the Fed to follow its historical policy rule of raising the funds rate in conjunction with oil price increases. We show that if the new policy rule were anticipated oil price increases would have had a much larger impact on output than suggested by Bernanke, Gertler, and Watson's analysis.

Charles T. Carlstrom is a senior economic advisor at the Federal Reserve Bank of Cleveland. Timothy S. Fuerst is an associate professor at Bowling Green State University and a research associate at the Bank.

Materials may be reprinted, provided that the source is credited. Please send copies of reprinted materials to the editor.

Policy Discussion Papers are published by the Research Department of the Federal Reserve Bank of Cleveland. To receive copies or to be placed on the mailing list, e-mail your request to 4dsubscriptions@clev.frb.org or fax it to 216-579-3050. Please send your questions comments, and suggestions to us at editor@clev.frb.org.

Policy Discussion Papers are available on the Cleveland Fed's site on the World Wide Web: www.clevelandfed.org/Research.

Views stated in Policy Discussion Papers are those of the authors and not necessarily those of the Federal Reserve Bank of Cleveland or of the Board of Governors of the Federal Reserve System. 


\section{Introduction}

Oil price increases have preceded every recession since 1971. Each of these recessions has also been preceded by an increase in the federal funds rate (see figure 1).Are recessions caused by the spikes in oil prices or a sharp tightening of monetary policy? Perhaps they are caused by a confluence of both factors, a so-called "perfect storm."

In an influential article, Bernanke, Gertler, and Watson (1997), hereafter BGW, tried to answer this question. Disentangling the effects of oil and monetary policy on output is extremely difficult, and BGW's novel contribution was to quantify the effects of each in a VAR analysis. ${ }^{1}$

BGW first report a baseline case in which these effects are not disentangled and the funds rate moves endogenously in response to the oil shock. Output falls sharply in this case. They then disentangle the effects by asking the following counterfactual question: How much would output have

1. There are, of course, numerous studies that analyze the effect of monetary shocks and oil shocks in isolation. See BGW (1997) for references. initial answer was surprising to many. If the Fed had kept the funds rate constant, output would have fallen only modestly. The endogenous response of monetary policy accounted for virtually all of the negative impact of oil shocks on the economy. Because their counterfactual experiment was related to previous work by other authors (Sims and Zha 1996), BGW called it the "Sims-Zha" experiment.

This Policy Discussion Paper examines BGW's conclusions. We first identify some problems with their empirical analysis, which have been pointed out previously, in particular, insufficient lag length and the possibility of spurious correlation. But our main focus is on a more serious problem with the BGW analysis. In the Sims-Zha experiment, the funds rate is counterfactually held at its pre-oil-shock level by adding exogenous unanticipated policy shocks to the funds rate.This is equivalent to an assumption that policy can systematically surprise the public, which is, of course, a highly questionable assumption. If the public becomes aware of a systematic movement in policy, the public's behavior

\section{FIGURE 1}

OIL PRICES AND EFFECTIVE FEDERAL FUNDS RATES

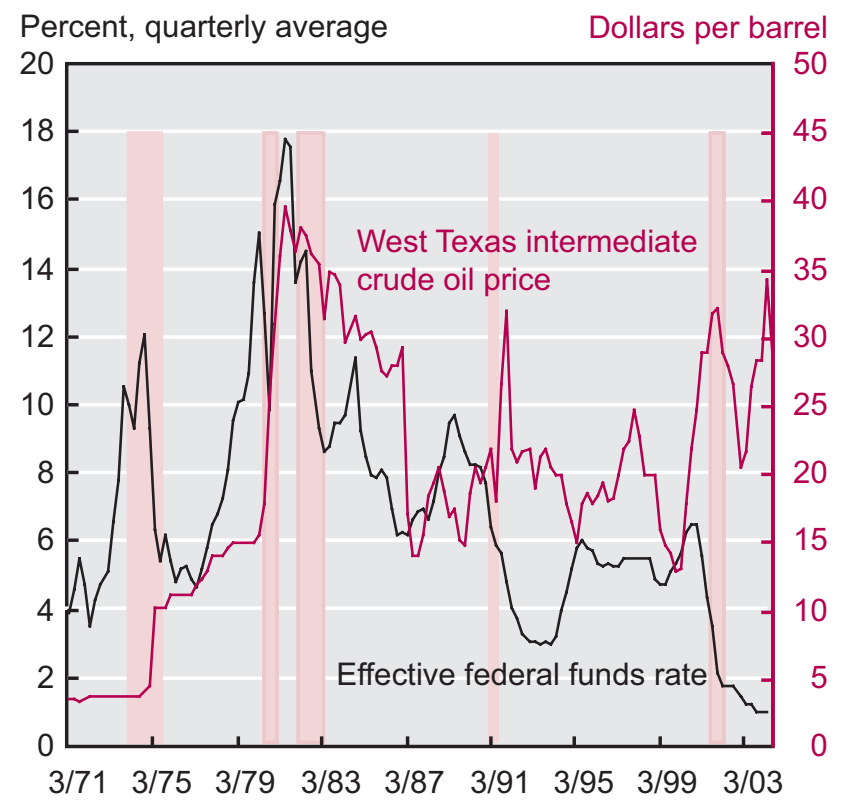

Note: Shaded bars indicate periods of recession.

Sources: Board of Governors of the Federal Reserve System, "Selected Interest Rates," Federal Reserve Statistical Releases, H.15; and Bloomberg Financial Services. 
will change in response, so that estimated VAR coefficients may not be invariant to systematic changes in monetary policy.This is an example of the celebrated "Lucas critique" (1976).

Since VAR modeling cannot address the quantitative importance of the Lucas critique, we build a small-scale, structural, computable general equilibrium (CGE) model. Within this theoretical model, we explicitly perform BGW's counterfactual experiment under two different assumptions:The funds rate behavior is anticipated or it is not. In our "unanticipated" Sims-Zha experiment, the central bank keeps the funds rate constant by repeatedly fooling the public.This corresponds exactly to BGW's empirical analysis. In our "anticipated" Sims-Zha experiment, the public anticipates that the central bank will keep the funds rate constant in the wake of the oil price shock. We also perform BGW's baseline case so that we can compare our model's results more meaningfully with BGW's.

The results of our model are similar to BGW's for both the baseline case and the unanticipated SimsZha experiment. However, when we consider the anticipated Sims-Zha experiment, we get a much different result. If the public correctly anticipates that the central bank will respond systematically to oil price movements in order to keep the funds rate stable, the economy contracts by roughly the same amount as in the baseline case. That is, once policy is anticipated, output falls as much as when the funds rate is allowed to increase endogenously. The sharp difference between the unanticipated and anticipated Sims-Zha experiments implies that expectations are critical, and the Lucas critique is quantitatively relevant. Thus, if the Fed had systematically held the funds rate constant after every oil shock, output would have declined by an amount comparable to the decline actually observed. In other words, the Fed cannot use systematic policy to avert output declines after oil price shocks.

\section{Oil Price Hikes and Output: Estimation Concerns}

Recall that BGW (1997) concluded that the characteristic decline in output after an oil price shock was almost entirely driven by monetary policy and not oil prices per se. According to BGW, if the funds rate had been kept constant after the shock, output would not have fallen significantly. In their comment on BGW (1997), Hamilton and Herrera (2004) suggest that BGW's conclusion is very sensitive to lag length. BGW estimated the impact of oil using monthly data with seven lags. Practically speaking, their analysis implicitly assumes that the exogenous impact of an oil price shock on the economy ends within seven months. But when Hamilton and Herrera (2004) increase the number of monthly lags from seven to twelve months, oil has a significant impact on the economy-even when the funds rate is held constant.

There are two possible explanations for why increasing the number of lags affects BGW's (1997) results so dramatically. One is that it may simply take a year or longer for oil price hikes to fully appear in GDP. If this is the case, then extra lag lengths seem warranted.The other explanation is that the effect is spurious. Introducing extra lags multiplies the number of additional parameters that need to be estimated. Estimating all of the extra lags introduces greater imprecision into the estimates, because more coefficients are being estimated. Hence, although the longer lag length suggests a larger effect for oil on the economy, that effect is estimated with greater error, so that one cannot be confident that it reflects oil's true effect.

Which lag length to use is an open question. In their response to Hamilton and Herrera, BGW (2004) run a quarterly version of their model with four lags. (The results of this experiment are reproduced in figure 2.) With the longer lag, the maximum impact of a 10 percent oil price shock with the endogenous increase in the funds rate is approximately a 0.7 percent decline in GDP. This is similar to their earlier result with a shorter lag length. But if the funds rate were not allowed to increase 

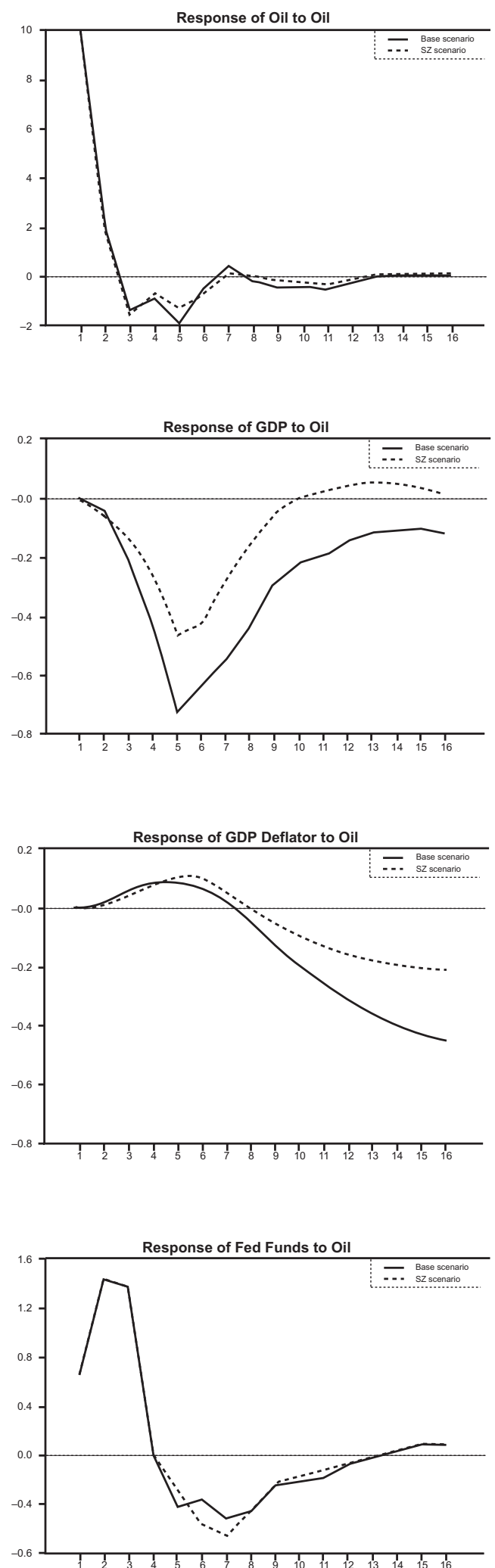

Source: Bernanke, Ben S., Mark Gertler, and Mark Watson, "Oil Shocks and Aggregate Macroeconomic Behavior: The Role of Monetary Policy A Reply," Journal of Money Credit and Banking, vol. 36, no. 2, April 2004, 287-91. 
(their Sims-Zha experiment), the decrease in output would have been muted considerably, falling by approximately half of that amount. Specifically, output would have declined approximately 0.4 percent.This stands in contrast to BGW (1997), where they argued that oil would have little independent effect on the economy.

It is instructive to put these numbers into context. Oil prices increased more than 50 percent between January 2004 and October 2004 (from \$34 to \$53 per barrel). If the funds rate were allowed to increase after this 50 percent oil price shock, we would expect output to decline by 3.5 percent! If the funds rate were held constant, however, their Sims-Zha experiment suggests that this same shock would reduce output by only 2 percent.

It is also instructive, however, to examine figure 2 more closely. Specifically, in BGW's (2004) baseline experiment, a 10 percent increase in the price of oil increased the funds rate by almost 1.5 percentage points. Given a 50 percent oil price increase, this implies that the funds rate would have increased by nearly 750 basis points. Put another way, their Sims-Zha experiment (keeping the funds rate constant) asks what would happen if we were to lower the funds rate by 7.5 percent in conjunction with the oil price hikes of 2004 . Even if you take the baseline funds rate to be 4 percent, as is currently suggested by the Taylor rule, this still amounts to lowering the funds rate to -3.5 percent, which is clearly nonsensical.

BGW's counterfactual Sims-Zha experiment implicitly assumes that the large hikes in the funds rate in the mid-1970s and early 1980s were entirely due to oil or the impact of oil on the economy. But this assumption is unlikely to be true.The period leading up to the 1975 recession may provide us with some guidance as to what the VAR estimates are picking up.

From the beginning of 1972 to the middle of 1974 , the Fed increased the funds rate nearly 10 percentage points (3.3 percent to 12.9 percent). There was also a huge jump in oil prices during this same period-oil prices tripled from $\$ 3.56$ per barrel in the middle of 1973 to $\$ 11.20$ at the end of 1974. But the huge run-up in interest rates was also preceded and likely caused by years of excessively easy monetary policy during the late 1960s and early 1970s. This resulted in a nearly 9 percentage point jump in actual inflation from 1972 to 1974 . Inflation expectations, while not observable, can certainly be expected to have risen as well around this time. These increases, however, were almost certainly not entirely due to the oil price shock, which began a little later.The funds rate increase was as likely to be caused by the Fed's earlier accommodation of rising inflation expectations as it was oil prices.

When inflation expectations rise, the Fed must increase the funds rate by same amount as the increase in expected inflation just to keep the real funds rate constant. Moving the funds rate from 1973 to 1975 as inflation expectations were increasing meant keeping monetary policy neutral. But today, when inflation expectations are steady, keeping the funds rate constant would be neutral policy. BGW's VAR estimates cannot shed any light on this hypothesis, as they cannot tease out the contribution oil makes to policy increases from that made by anything else. If there were shocks to expected inflation unrelated to the oil price shock, then BGW's VAR results could be interpreted to say that if the Fed were to run an excessively easy and accommodative monetary policy, then output would not have declined as much. This suggests that spurious correlation may be driving some of their results and that the results of their Sims-Zha experiment are likely to be overestimated. 


\section{Oil Prices and Monetary Policy:A CGE Model}

A more serious concern with BGW $(1997,2004)$ is the potential quantitative relevance of the Lucas critique. BGW (1997) are clearly cognizant of the critique. They claim, however, that "it seems plausible to us that a purely transitory deviation from the usual policy rule would not significantly affect the structure of the economy (that is, the quantitative effect of the Lucas critique should be small)." But this is just a conjecture on their part. To assess the importance of the critique it is necessary to use a model such as the one we develop in this paper. We construct a calibrated computable general equilibrium model, which can fully account for Lucas critique effects.

To have a point of reference for comparison, we first use our model to replicate the two experiments of BGW's 2004 analysis, the baseline and the Sims-Zha (the unanticipated Sims-Zha in our model). For our model's estimates to be taken seriously, the results of our baseline and unanticipated Sims-Zha experiments should be roughly similar to those generated from BGW's (2004) VAR data. We use BGW's (2004) quarterly VAR as our empirical benchmark because it is less prone to lag-length problems and because our theoretical model is quarterly. In what follows, BGW refers to BGW (2004). The appendix presents a brief description of our model and the calibration of its parameters.

A key issue in the analysis is, of course, the statement of monetary policy. For the baseline simulation, we assume that policy is given by the following Taylor-type rule:

$$
R_{t}=\tau \pi_{t}+\tau_{y} y_{t}+\eta_{t}
$$

where $R_{t}$ denotes the net nominal interest rate as a deviation from the steady state, $\pi_{t}$ denotes the inflation rate as a deviation from the steady state, and $y_{t}$ denotes output as a log deviation from the steady state. The variable $\eta_{t}$ can be interpreted as "policy errors," which we assume are i.i.d. across time. For the baseline experiment $\eta_{t}=0$. Empirical evidence suggests that, since 1983, the coefficients in such a monetary policy rule are $\tau=1.53$ and $\tau_{y}=0.27$ (Kozicki 2002).

In our unanticipated Sims-Zha experiment interest rates are held constant for four quarters or equivalently,

$$
\eta_{t}=-\tau \pi_{t}-\tau_{y} y_{t} \text { for } t=1 \text { to } 4
$$

Note the systematic surprises here: The unanticipated Sims-Zha experiment assumes that households anticipate $\eta_{t}$ to be white noise when, in fact, it is a function of inflation and output.

In the anticipated Sims-Zha experiment everyone understands that the central bank is going to keep the funds rate constant for four quarters by systematically reacting to oil prices. The Taylor rule is now given by

$$
R_{t}=\tau \pi_{t}+\tau_{y} y_{t}+\tau_{1}^{o i l} p_{t}^{o i l}+\tau_{2}^{o i l} p_{t-1}^{o i l}+\tau_{3}^{o i l} p_{t-2}^{o i l}+\tau_{4}^{o i l} p_{t-3}^{o i l}
$$

where $\tau_{j}^{\text {oil }}$ (for $j=1$ to 4 ) are chosen so that the impact of an oil shock on interest rates is zero for four quarters. More details on the analysis are contained in Carlstrom and Fuerst (2004). 


\section{Oil Prices and Monetary Policy: Some Simulations}

Figure 3 shows the effect of a 10 percent oil price shock on real GDP.The baseline experiment allows the funds rate to increase as it responds to the systematic part of monetary policy. In contrast to BGW's VAR exercise, where the impact of a 10 percent oil price shock (and the ensuing funds rate increase) was a fall in output of around 0.7 percent, we estimate the effect to be approximately 0.45 percent. Given a 50 percent oil price hike, this amounts to a decline in output of 2.3 percent.The simple model we build and estimate does not include any of the lags that are obviously important in the data.Therefore, this number should not necessarily be thought of as a one-time drop in output growth of 2.3 percent. Instead, it may show up as something that lowers output growth on average by something like 0.6 percent per quarter over the course of a year.Thus, the current oil shock is not likely to cause a recession but something more akin to the "soft patch" suggested by Chairman Greenspan.

Figure 3 also illustrates our model's estimates of BGW's Sims-Zha experiment (our unanticipated Sims-Zha), where the funds rate is held constant. Like BGW, we estimate that the negative impact of oil on real GDP is smaller than the baseline case, now 0.2 percent for a 10 percent oil price hike. Figure 3 also shows, however, a more striking difference between our estimates and BGW's. In BGW's baseline experiment, the funds rate increases 1.5 percent, but in ours, it increases only 0.5 percent. Recall that we argued earlier that BGW's funds rate responses were probably overestimated.

In BGW's (2004) Sims-Zha experiment, monetary policy had to respond (negatively) to oil prices directly to keep interest rates from increasing 1.5 percent. Our model implies instead that a 10 per-

\section{\begin{tabular}{l|l} 
FIGURE 3 & SIMULATED INFLATION, OUTPUT, AND NOMINAL INTEREST RATE
\end{tabular}}
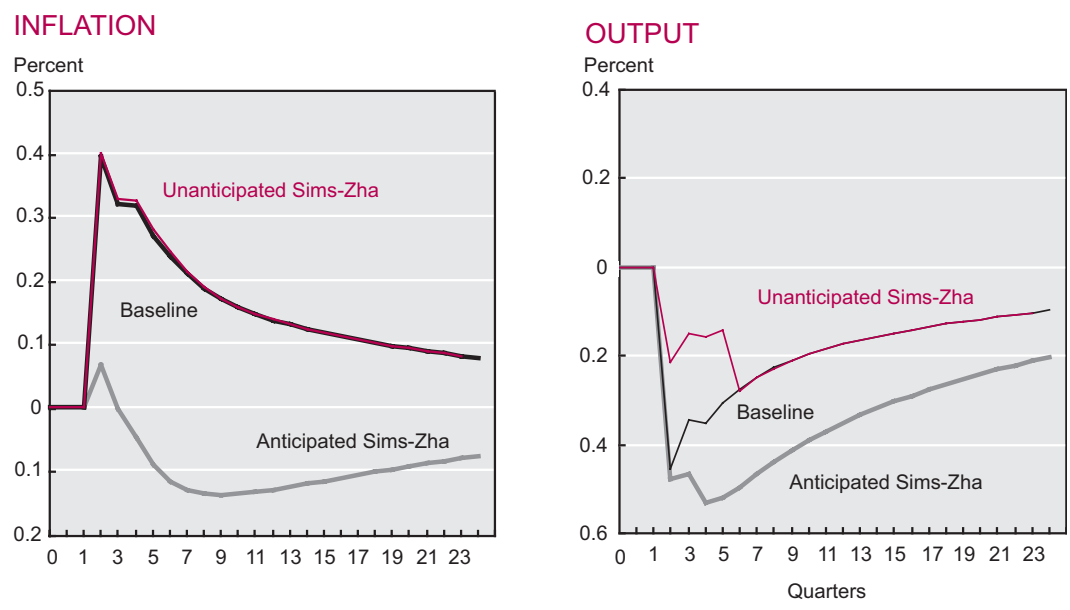

NOMINAL INTEREST RATE

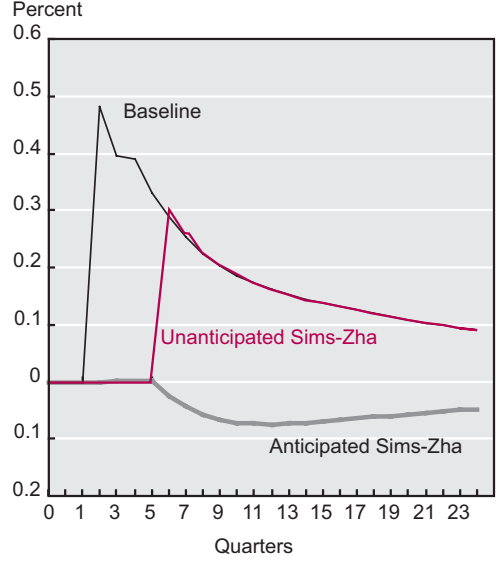

Source: Authors' calculations. 
cent oil price shock would push up the nominal rate only 0.5 percent. The impact of such a difference on the funds rate that would result after the recent 50 percent oil price increase is especially dramatic. BGW's estimates imply that the nominal rate would rise 750 basis points, so that the Sims-Zha experiment would require an aggressive loosening of policy that is not possible given the recent level of the funds rate. In contrast, our model implies a funds rate movement of only 2.5 percent. To put these numbers in context, note that the current Taylor rule estimate for the funds rate is around 4 percent, so that a 750 basis point decline is nonsensical.

Our unanticipated Sims-Zha experiment might suggest that a pause in the Fed's attempt to gradually increase the funds rate to something that roughly resembles the Taylor rule might be in order. Figure 3 suggests that the impact on inflation would be small. But before accepting this conclusion, we will investigate how sensitive it is to assumptions about expectations and ask whether its validity is affected by alternative assumptions.

\section{The Relevance of the Lucas Critique}

While the unanticipated Sims-Zha experiment may help us determine the impact of a one-time deviation from a Taylor-type rule, where the Fed responds to oil prices to keep the funds rate constant, it is not at all clear that it tells us what would happen if this endogenous response to oil were anticipated.Another way to think of this problem is: What would happen to output if the Fed were to respond systematically to oil price increases in such a way as to keep the funds rate constant after an oil price shock?

Our anticipated Sims-Zha experiment addresses this issue by incorporating a systematic monetary response to oil into the monetary policy rule, namely, that if oil prices rise, the funds rate should stay constant. Because the monetary policy response to oil is systematic, the public would anticipate the constant funds rate, and inflation expectations would adjust accordingly.

In sharp contrast to BGW's assertion that expectations are likely to have a small and insignificant effect on their results, figure 3 indicates otherwise. The Lucas critique is quite relevant and quantitatively significant.The unanticipated Sims-Zha experiment had output declining by a small 0.2 percent. Once this effect becomes anticipated, however, the effect increases dramatically to -0.48 percent. In fact, the response of output to a 10 percent oil price shock is essentially the same as it was in our baseline experiment, where interest rates are allowed to increase endogenously in response to the increase in oil prices.

The impact of expectations is clear. In the unanticipated Sims-Zha experiment, when oil prices rise, the monetary authority keeps the funds rate constant even though the monetary policy rule calls for an increase. The only way to do this in the real world is to take the public by surprise. Keeping the funds rate contant when everyone expects it to rise amounts to an unexpected decline in the funds rate and is thus expansionary relative to the baseline case. Hence, output falls less than it would have otherwise. But once this constant funds rate is anticipated, matters are much different. Output responds in the anticipated Sims-Zha experiment in essentially the same way as in the benchmark case, where the funds rate increases in response to oil price hikes. These results demonstrate that if expectations are not modeled explicitly, it is not possible to disentangle the quantitative effects of oil shocks and monetary policy on the economy. 


\section{Conclusion and Policy Advice}

This paper presents evidence that indicates the likely effect of an oil price shock on output and inflation. We do this by modeling two hypothetical relationships between oil and the funds rate-one in which the funds rate increases endogenously because of oil's impact on inflation and output, and one in which the Fed actively offsets this rate increase by holding the funds rate constant. Furthermore, we show the effect of this latter experiment under two different scenarios-one in which the Fed engineers the constant fed funds rate by systematically fooling the public (replicating BGW's SimsZha experiment), and another in which the Fed's new reaction function is anticipated. By "fooling" the public we mean that the public expects the Fed to follow its policy rule, which calls for it to raise the funds rate, but instead the Fed keeps the rate constant. Contrary to BGW's hunch, we show that when the new policy rule is anticipated, it makes a large and important difference on output.

The policy implication of this difference is clear. Our simulation of the Sims-Zha experiment suggests that delaying further increases in the funds rate could help the economy through the "soft patch" caused by the recent oil price hikes-without increasing the chance of inflation. But our anticipated Sims-Zha experiment demonstrates the downside of such a choice. The only reason a constant fed funds rate would keep output from declining as much as it should after a big spike in oil prices is because people don't expect the Fed to do it. It might work this time, but responding to oil price increases in the same way every time will eventually be anticipated by the public and lead to even larger output losses. 


\section{References}

Bernanke, Ben S., Mark Gertler, and Mark Watson. 1997."Systematic Monetary Policy and the Effects of Oil price Shocks," Brookings Papers on Economic Activity 1, 91-142.

Bernanke, Ben S., Mark Gertler, and Mark Watson. 2004. "Oil Shocks and Aggregate Macroeconomic Behavior:The Role of Monetary Policy, A Reply," Journal of Money, Credit, and Banking, vol. 36, no. 2 (April), 287-91.

Calvo, Guillermo. 1983. "Staggered Prices in a Utility-Maximizing Framework," Journal of Monetary Economics, vol. 12,383-98.

Carlstrom, Charles T., and Timothy S. Fuerst. 2004. "Oil Prices, Monetary Policy, and Expectations," unpublished manuscript.

Erceg, Christopher J., Dale W. Henderson, and Andrew T. Levin. 2000. “Optimal Monetary Policy with Staggered Wage and Price Contracts,"Journal of Monetary Economics, vol. 46, 281-313.

Hamilton, James D., and Ana Maria Herrera. 2004. "Oil Shocks and Aggregate Macroeconomic Behavior:The Role of Monetary Policy,'Journal of Money, Credit, and Banking, vol.36, no. 2 (April), 265-86.

Kozicki, Sharon. 1999. "How Useful Are Taylor Rules for Monetary Policy?" Federal Reserve Bank of Kansas City, Economic Review, vol. 84, no. 2, 5-33.

Kim, In-Moo, and Prakesh Loungani. 1992."The Role of Energy in Real Business Cycle Models,”Journal of Monetary Economics, vol. 29, no. 2, 173-90.

Lucas, Robert E.,Jr. 1976. "Econometric Policy Evaluation:A Critique," Carnegie-Rochester Conference Series on Public Policy 1, 19-46.

Sims, Christopher A., and Tao Zha. 1996. "Does Monetary Policy Generate Recessions?" unpublished manuscript, Princeton University.

Walsh, Carl. 2003. Monetary Theory and Policy, Cambridge, Mass.: MIT Press.

Woodford, Michael. 2003. Interest and Prices, Princeton and Oxford: Princeton University Press.

Yun,Tack. 1996. "Nominal Price Rigidity, Money Supply Endogeneity, and Business Cycles," Journal of Monetary Economics, vol. 37, no. 2,April, 345-70. 


\section{The Model}

Other than the addition of oil to the production technology, the underlying model is fairly standard. See Woodford (2003) and Walsh (2003) for details. In this appendix, we will sketch the framework. The theoretical model consists of households and firms. We present the decision problems of each in turn.

\section{Housebolds}

Households are infinitely lived, discounting the future at rate $\beta$. Their period-by-period utility function is given by

$$
U\left(C_{t}, L_{t}, \frac{M_{t+1}}{P_{t}}\right) \equiv \frac{C_{t}^{1-\sigma}}{1-\sigma}-\frac{L_{t}^{1+\gamma}}{1+\gamma}+V \frac{M_{t+1}}{P_{t}},
$$

where $\sigma>0, \gamma>0, V$ is increasing and concave, $C_{t}$ denotes consumption, $L_{t}$ denotes labor, and $\frac{M_{t+1}}{P_{t}}$ denotes real cash balances, which can facilitate time-t transactions. The household begins period $t$ with $M_{t}$ cash balances and $B_{t-1}$ one-period nominal bonds that pay $R_{t-1}$ gross interest. With $w_{t}$ denoting the real wage, $P_{t}$ the price level, and $X_{t}$ the time- $t$ monetary injection, the household's intertemporal budget constraint is given by

$$
P_{t} C_{t}+B_{t}+M_{t+1} \leq m_{t}+R_{t-1} B_{t-1}+P_{t} w_{t} L_{t}+X_{t}
$$

The household's portfolio choice is given by

$$
\begin{gathered}
\frac{V^{\prime}\left(M_{t+1} / P_{t}\right)}{C_{t}^{-\sigma}}=\frac{R_{t}-1}{R_{t}} \\
C_{t}^{-\sigma}=R_{t} \beta C_{t+1}^{-\sigma} / \pi_{t+1} .
\end{gathered}
$$

Following Erceg, Henderson, and Levin (2000), we assume that households are monopolistic suppliers of labor and that nominal wages are adjusted as in Calvo (1983). In this case labor supply behavior is given by

$$
C_{t}^{\sigma} L_{t}^{\gamma}=Z h_{t} W_{t}
$$

It is easy to see that the wage elasticity of labor demand in this model is $1 / \gamma$. The variable $Z b_{t}$ in this labor demand equation is the monopoly distortion as it measures how far the household's marginal rate of substitution is from the real wage. In the case of perfectly flexible but monopolistic wages, $\boldsymbol{Z} \boldsymbol{b}_{\boldsymbol{t}}=\boldsymbol{Z} \boldsymbol{b}$ is constant and less than unity.The smaller is $\boldsymbol{Z} \boldsymbol{b}$, the greater is the monopoly power. In the case of sticky nominal wages, $Z \boldsymbol{b}_{\boldsymbol{t}}$ is variable and moves in response to the real and nominal shocks hitting the economy. Erceg et al. (2000) demonstrate that in log deviations nominal wage adjustment is given by

$$
\pi_{t}^{W}=\lambda^{W} z h_{t}+\beta \pi_{t+1}^{W}
$$

where $\pi_{t}^{W}$ is time-t net nominal wage growth, and $z \boldsymbol{h}_{t}$ denotes the log deviation from steady-state. 
Firms

The firms in the model utilize labor services, $L_{t}$, from households, and energy, $E_{t}$, from external sources to produce the final good using the CES technology:

$$
Y=f(L, E) \equiv\left[(1-a) L^{1-\rho}+a E^{1-\rho}\right]^{1 /(1-\rho)} \text {. }
$$

The real energy price is equal to $p_{t}^{e}$ so that a firm's nominal profits are given by

$$
\text { profits }=P_{t}\left(Y_{t}-w_{t} L_{t}-p_{t}^{e} E_{t}\right)
$$

The firm is a monopolistic producer of these goods, implying that labor will be paid below its marginal product. Let $Z_{t}$ denote marginal cost so that we have

$$
\begin{aligned}
& w_{t}=Z_{t} f_{L}(t) \\
& p_{t}^{e}=Z_{t} F_{E}(t) .
\end{aligned}
$$

The variable $Z_{t}$ is the monopoly distortion as it measures how far the firm's marginal products differ from the real factor prices. In the case of perfectly flexible but monopolistic prices, $Z_{t}=Z$ is constant and less than unity.The smaller is $Z$, the greater is the monopoly power. In the case of sticky prices, $Z_{t}$ is variable and moves in response to the real and nominal shocks hitting the economy.Yun (1996) demonstrates that in log deviations nominal price adjustment is given by

$$
\pi_{t}=\lambda z_{t}+\beta \pi_{t+1}
$$

where $\pi_{t}$ is time-t nominal price growth (as a deviation from steady-state nominal price growth) and lower case $z_{t}$ denotes the log deviation from steady-state.

\section{Equilibrium and Policy}

There are four markets in this theoretical model: the labor market, the goods market, the bond market, and the money market. The respective market-clearing conditions include: $C_{t}=Y_{t}-p_{t}^{e} E_{t}$ and $B_{t}$. The money market clears with the household holding the per capita money supply intertemporally.

\section{Unanticipated Sims-Zha Experiment}

BGW's Sims-Zha experiment corresponds to the following monetary policy rule. In log deviations the monetary policy rule is given by a Taylor-type interest rate rule

$$
R_{t}=\tau \pi_{t}+\tau_{y} y_{t}+\eta_{t}
$$

where $y_{t}$ denotes $\log$ deviations in real output. In addition, $\eta_{t}$ can be interpreted as "policy errors," and we assume it is i.i.d. across time. ${ }^{2}$ For the baseline experiment, $\eta_{t}=0$. In the Sims-Zha experiment interest rates are held constant for 4 quarters or equivalently,

$$
\eta_{t}=-\tau \pi_{t}-\tau_{y} y_{t} \text { for } t=1 \text { to } 4
$$

Note the systematic surprises here:The Sims-Zha experiment assumes that households anticipate $\eta_{t}$ to be white noise when, in fact, it is a function of inflation and output. 


\section{Anticipated Sims-Zha}

In the anticipated Sims-Zha experiment everyone understands that the central bank is going to keep the funds rate constant for 4 quarters by systematically reacting to oil prices. The Taylor rule is now given by

$$
R_{t}=\tau \pi_{t}+\tau_{y} y_{t}+\tau_{1}^{o i l} p_{t}^{o i l}+\tau_{2}^{o i l} p_{t-1}^{o i l}+\tau_{3}^{o i l} p_{t-2}^{o i l}+\tau_{4}^{o i l} p_{t-3}^{o i l},
$$

where $\tau_{j}^{o i l}$ (for $j=1$ to 4 ) are chosen so that the impact of an oil shock on interest rates is zero for 4 quarters.

\section{Calibration}

Before proceeding with the analysis, we need to set parameter values at levels consistent with empirical estimates for a quarterly model. Preference parameters are given by $\beta=0.99$ (implying a 4 percent annual steady-state real rate of return), $\sigma=2$, and $\gamma=3$.The latter values are consistent with micro evidence of fairly inelastic savings and labor supply behavior. Since monetary policy is given by an interest-rate-targeting procedure, the nature of the utility of money is irrelevant. Finally, we assume that prices and nominal wage levels can be adjusted on average every 2.9 quarters. Given the other preference parameters, this implies $\lambda=0.19$ and $\lambda^{w}=0.0146$.

As for firms, the elasticity of substitution between oil and labor is equal to $1 / \rho$. Consistent with empirical estimates, we set this elasticity to 0.59 , or $\rho=1.7$ (Kim and Loungani (1992). The share parameter $a$ is set to 0.02 . This implies a share of energy in total output of 6 percent (consistent with its share in 1989).

The (logged) real price of oil is given by an exogenous $\operatorname{AR}(2)$ process

$$
p_{t}^{e}=a_{1} p_{t-1}^{e}+a_{2} p_{t-2}^{e}+\varepsilon_{t}
$$

Estimating this process yields $a_{1}=1.12$ and $a_{2}=-0.15$.

Finally, recall that monetary policy in the baseline experiment is given by

$$
R_{t}=\tau \pi_{t}+\tau_{y} y_{t}
$$

Empirical evidence presented in Kozicki (2002) suggests that since 1983 the coefficients in this monetary policy rule are $\tau=1.53$ and $\tau_{y}=0.27$. 


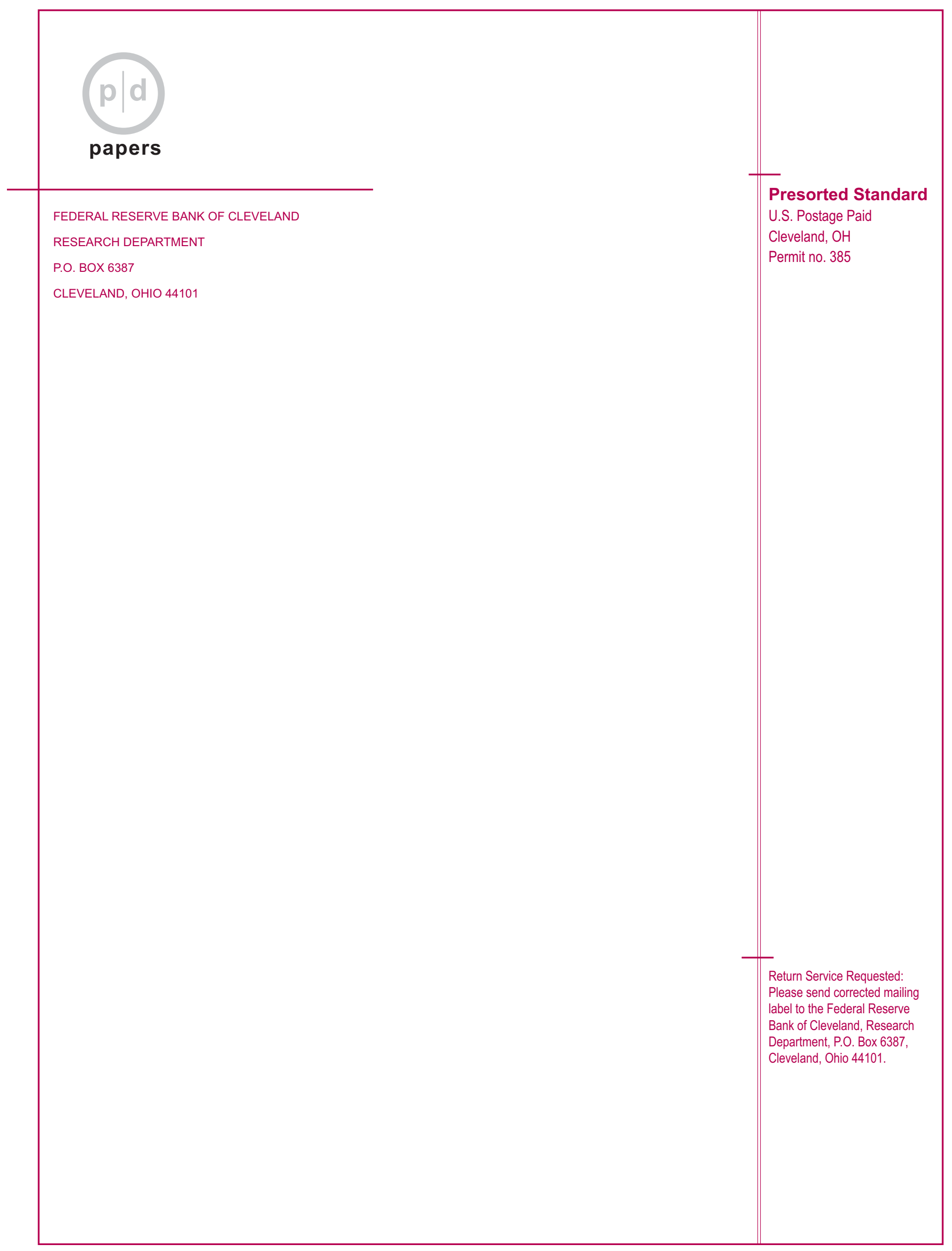

